\title{
Porites superfusa mortality and recovery from a bleaching event at Palmyra Atoll, USA
}

\author{
Kathryn Anne Furby Corresp., ${ }^{1}$, Jennifer Ellen Smith ${ }^{1}$, Stuart Adrian Sandin ${ }^{1}$ \\ ${ }^{1}$ Scripps Institution of Oceanography, University of California San Diego, San Diego, United States \\ Corresponding Author: Kathryn Anne Furby \\ Email address: kfurby@ucsd.edu
}

Background. The demography of a coral colony is not a binary trajectory of life and death. Based on the flexibility afforded by colonial organization, most reef-building corals employ a variety of dynamic survival strategies, including growth and shrinkage. The demographic flexibility affects coral size, shape and reproductive output, among other factors. It is thus critical to quantify the relative importance of key dynamics of recruitment, mortality, growth and shrinkage in changing the overall cover of coral on a reef.

Methods. Using fixed photographic quadrats, we tracked the patterns of change in the cover of one common central Pacific coral, Porites superfusa, before and after the 2009 ENSO event.

Results. Coral colonies suffered both whole and partial colony mortality, although larger colonies were more likely to survive. In subsequent years, recruitment of new colonies and regrowth of surviving colonies both contributed to the modest recovery of $P$. superfusa.

Discussion. This study is unique in its quantitative comparisons of coral recruitment versus regrowth during periods of areal expansion. Our data suggest that recovery is not limited simply to the long pathway of settlement, recruitment and early growth of new colonies but is accelerated by means of regrowth of already established colonies having suffered partial mortality. 
1 Porites superfusa mortality and recovery from a bleaching event at Palmyra Atoll, USA

2 Kathryn Anne Furby ${ }^{1 *}$, Jennifer E. Smith ${ }^{1}$, Stuart A. Sandin ${ }^{1}$

3 ' ${ }^{1}$ Scripps Institution of Oceanography, University of California San Diego, San Diego, USA

4

5 Corresponding Author:

$6 \quad$ Kathryn Furby ${ }^{1}$

7

8 


\section{Introduction}

10 Understanding patterns of mortality and recovery among reef-building corals is

11 foundational to the development of accurate predictions of coral population trajectories (Baird \&

12 Marshall 2002). Recruitment has been recognized as important for long-term recovery after

13 major and frequent disturbances, especially for coral populations that have suffered widespread,

14 whole-colony mortality (Dollar \& Tribble 1993). However, many disturbance events are less

15 extreme, leading to a combination of partial and complete mortality. We define partial mortality

16 of colonial corals as the response to a stress event that leads to tissue loss, but with the survival

17 of some colony area. For colonies suffering from partial mortality, regeneration of tissue

18 following stress is a critical mechanism in assuring individual colony survival (Chadwick \&

19 Loya 1990). As such regrowth of corals has been suggested as an important mechanism in coral

20 population recovery (Diaz-Pulido et al., 2009; Gilmour et al., 2013). In this context, analyzing

21 recovery characteristics can help project population resilience.

22 Given the colonial nature of most reef-building corals, the definition of an 'individual'

23 presents real challenges (Hughes, Ayre \& Connell 1992). Coral ecological literature often refers

24 to an individual as a colony. Interactions and population dynamics are sometimes best described

25 at the colony scale, including patterns of size-specific mortality, competition for space on the

26 benthos, and vulnerability to storm damage (e.g., Hughes \& Jackson 1980; McCook, Jompa \&

27 Diaz-Pulido 2001; Baird \& Marshall 2002; Madin et al., 2014). In contrast the physiological

28 definition of an individual is the polyp (Harper 1985). In particular both asexual (fission/

29 budding) and sexual (spawning/ brooding) modes of reproduction occur at the scale of the polyp.

30 When tracking demographic responses to environmental change or disturbance, it is critical to

31 account for dynamics occurring at both the scale of the colony and the scale of the polyp. 

mortality, partial colony mortality (tissue loss), recruitment, and partial-colony growth

34 (sometimes referred to as regrowth) (Fig 1). A few recent studies have documented the relative importance of recruitment and regrowth as mechanisms of coral population recovery following a disturbance (Diaz-Pulido et al., 2009; Gilmour et al., 2013; Roff et al., 2014), however, the colonial mechanisms of coral recovery have not been regularly quantified.

Due to its remote location and lack of local anthropogenic impacts, Palmyra Atoll is an ideal location for studying demographic rates of corals in response to global change (Knowlton \& Jackson 2008; Sandin et al., 2008; Williams et al., 2011). Palmyra is a US National Wildlife protected from fishing and other impacts. In 2009, Palmyra Atoll experienced a mild bleaching event associated with an El Nino Southern Oscillation (ENSO) event (Williams et al., 2010).

During the $2009 \mathrm{ENSO}$ event, sea surface temperatures reached $1.5^{\circ} \mathrm{C}$ above the maximum longterm monthly temperatures, and the anomaly continued for four months (Williams et al., 2014). October 2009 through March 2010 had over 4 DHW (degree heating weeks) with November through March over 8 DHW (NOAA Coral Reef Watch).

This study examines patterns of change in an encrusting coral, Porites superfusa, on Palmyra Atoll during and after the thermal stress event. Specifically, our objectives were to address two complementary questions: (1) Does $P$. superfusa cover change through time from 2009 to 2012 on Palmyra Atoll? (2) What are the relative rates of colony survivorship

52 (recruitment/ mortality) versus colony growth (growth/ shrinkage) during and after a bleaching 53 event? 


\section{Materials \& Methods}

\section{Study Species}

Porites superfusa is a small coral that is relatively ubiquitous on Palmyra Atoll, reaching

58 almost $400 \mathrm{~cm}^{2}$ in area with an overall mean colony size of $9.9 \mathrm{~cm}^{2}\left(\right.$ median $\left.=4.4 \mathrm{~cm}^{2}\right)$. Our

59 targeted design involved this species because it is one of the most numerous corals in the area,

60 and its compact morphology allows study of multiple individuals within square meter

61 photoquadrats (see below). In 2009, the P. superfusa population showed extensive evidence of

62 bleaching with a notable reduction in cover in the permanent photoquadrats.

63

64 Surveys

65 Four forereef sites on Palmyra Atoll were selected, two sites on the north and two sites on

66 the south shore, each approximately $2 \mathrm{~km}$ apart (Fig 2). Sites were chosen to be representative of

67 Palmyra's forereef habitats. These sites all had high initial densities $\left(\mathrm{C}_{2009}\right)$ of Porites superfusa

68 colonies, and as they are evenly spaced across the island they should capture within-island

69 differences in the forereef habitat. Sites were surveyed four times at approximately annual

70 intervals (September 2009, July 2010, September 2011, and September 2012).

At each site, one $50 \mathrm{~m}$ transect was permanently marked, parallel to shore and at a depth

72 of $10 \mathrm{~m}$. In 2009, ten permanent photoquadrats were established at each site, positioned every 5

$73 \mathrm{~m}$ along the transects. The corners of plots were marked with stainless steel eyebolts held in

74 place with marine epoxy (US Fish and Wildlife Special Use Permit 12533-16006). Each

75 photoquadrat was imaged with a Canon G12 camera attached to a PVC frame $\left(0.54 \mathrm{~m}^{2}\right)$ by

76 SCUBA divers (Sandin et al., 2008). These marked plots were revisited and re-surveyed, 
77 enabling the tracking of individual colony fates through time. In sum, $400.54 \mathrm{~m}^{2}$ plots were

78 surveyed annually for a total of four time points each.

79

80 Image analyses

81 Within each photograph, colonies of $P$. superfusa ranged in area from $0.2 \mathrm{~cm}^{2}$ to 440

$82 \mathrm{~cm}^{2}$. Due to the limitations of the photographic resolution, the tracking of the smallest colonies

83 was not possible and thus we focused our study on colonies exceeding $1 \mathrm{~cm}^{2}$. Photographs were

84 analyzed using ImageJ to calculate the size (estimated as 2-dimensional area when viewed from

85 the top down) and survivorship of each P. superfusa colony within the images (Fig 3, Abramoff,

86 Magalhaes \& Ram 2004). Each colony was tagged digitally and tracked through time (similar to

87 methods of Hughes \& Jackson 1985). Fates of the colonies were placed into one of five

88 categories - complete mortality, partial mortality, true recruits, growth, and 'resurrected'

89 recruits. Complete mortality was defined as the death of the entire visible coral, with its previous

90 location overgrown by other organisms (Fig 3B-1). Partial mortality (i.e., injury, shrinkage) was

91 recorded when colonies lost tissue (Fig 3B-2). True recruitment (or settlement) indicated a new

92 coral recruit had claimed substrate in an area previously without P. superfusa (Fig 3B-3). Growth

93 occurred when a previously present colony created additional tissue (Fig 3B-4). 'Resurrected'

94 recruits were defined as apparent recruits that appear in a location where a colony had been

95 recorded as suffering mortality in previous time points (Fig 3C-5, Fig 1). Because of the

96 limitations of the photographic census, it was impossible to determine whether such recruits were

97 new recruits (new colony settling at the same location) or regrowth from microscopic areas of

98 cryptic remnant tissue. Individual colony cover and total P. superfusa cover were calculated per 
99 quadrat. Data are reported in two formats: colony-specific fates and total live $P$. superfusa cover

100 summed within quadrats tracked through time.

101

102 Data analyses

103 Analyses assessed patterns of variation in starting live $P$. superfusa cover across sites,

104 thus determining whether changes through time were similar among years. One-sample t-tests

105 were used to calculate differences of $P$. superfusa cover among sites in 2009 and to determine

106 differences between absolute change and proportional change in coral cover between time points.

107 Absolute change was the difference in coral surface area $\left(\mathrm{cm}^{2}\right)$ per quadrat (e.g., cover in $2010-$

108 cover in 2009 , or $\mathrm{C}_{2010}-\mathrm{C}_{2009}$ ). Proportional change was the relative difference in coral cover

109 between time points compared to the original coral cover in 2009 (e.g., $\left[\mathrm{C}_{2010}-\mathrm{C}_{2009}\right] / \mathrm{C}_{2009}$ ).

110 Tukey's post-hoc tests were used to determine potential differences among sites.

111 Because the same individual colony can appear in multiple years, analyses assessed the

112 possible effect of independence of colonies through time. ANCOVA was used to determine

113 interaction effects of year and site. Because 109 colonies were repeatedly assessed, data were

114 randomly sampled using each colony only once. A binomial logistic regression was used to

115 determine the effect of colony size on survivorship across years. Analyses were performed using

116 R version 3.1.2 (R Development Core Team, www.r-project.org).

\section{Results}

120 The 2009 temperature rise impacted approximately $75 \%$ of the Porites superfusa

121 population at Palmyra Atoll with bleaching and mortality observed island-wide. The initial size 
122 of individual colonies was greater on average than in subsequent years. The number of colonies

123 present in 2009 was also greater than in later time points. True recruit numbers in 2010 (after the

124 bleaching event of 2009) were lower than in 2011 and 2012 (Supplementary Table 1).

125 All sites surveyed exhibited similar patterns of decline in P. superfusa from 2009 to

126 2010, followed by fluctuations of growth in 2011 and 2012 (Fig 4, 5). From 2009 to 2010, P.

127 superfusa mortality was ubiquitous across sites, and the growth for this period was the lowest

128 observed during the study (Fig 4). Mortality was divided into two categories: complete and

129 partial mortality. These mechanisms contributed similarly to the reduction in cover observed (Fig

130 4, partial mortality: $-101.8[56.79] \mathrm{cm}^{2}$ per quadrat, mean [SE], complete mortality: -105.7

131 [39.10] $\mathrm{cm}^{2}$ per quadrat, mean [SE]). Recruitment and growth were minimal initially, revealing

132 no appreciable difference among growth mechanisms (Fig 4, Recruit: 4.99 [1.31] $\mathrm{cm}^{2}$, Growth:

$1334.56[0.69] \mathrm{cm}^{2}$ per quadrat). Across the study duration, the highest rates of growth were

134 observed from 2010 to 2011. Resurrected recruits (i.e., apparent recruits that appear in a location

135 where a colony had been recorded as suffering mortality in previous time points) made up a third

136 of total "recruitment" $\left(12.45[4.45] \mathrm{cm}^{2}\right)$. Recruitment contributed less than colonial growth to

137 the overall gain in cover (Fig 4, Recruit: 24.06 [8.77] $\mathrm{cm}^{2}$, Growth: $39.84[13.19] \mathrm{cm}^{2}$ ). From

1382011 to 2012 , resurrected recruits played a decreased role $\left(2.702[0.49] \mathrm{cm}^{2}\right)$ in population

139 growth. True recruitment and growth contributed similarly to overall growth (Recruit: 14.29

$140[18.37] \mathrm{cm}^{2}$, Growth: $\left.18.37[6.45] \mathrm{cm}^{2}\right)$.

141 In 2011,83 of over 400 colonies (21\%) reappeared (after being overgrown by turf and

142 crustose coralline algae in 2010) and began to re-colonize the substrate 10 months later

143 (resurrected recruits, Supplementary Table 1). Out of 1150 colonies tracked, approximately 100

144 fragmented into apparent daughter clones (due to partial mortality) and 79 fused. Of the 100 
145 colonies that fragmented, 52 fused back with a remnant section of the original colony within 2 146 years.

This study found that $P$. superfusa colonies gained upwards of $80 \mathrm{~cm}^{2}$ of new tissue area

148 per year and lost up to $170 \mathrm{~cm}^{2}$ of tissue area per year, with a mean tissue change of $\mid 4.75[0.232]$

$149 \mathrm{~cm}^{2} \mid$ per colony. During the time period that included the bleaching event from 2009 to $2010, P$.

150 superfusa declined an average of $8.3 \mathrm{~cm}^{2}$ per quadrat (total quadrat size, $540 \mathrm{~cm}^{2}$ ). From 2010 to

151 2011, the corals increased an average of $1.7 \mathrm{~cm}^{2}$ per quadrat (Welch two sample $\mathrm{t}$-test, $\mathrm{t}=-3.74$,

$152 \mathrm{p}=0.028)$ and from 2011 to 2012 corals declined an average of $0.9 \mathrm{~cm}^{2}$.

153 Average change in area, when normalized to initial coral size in 2009, was largely

154 negative (Fig 4, 5) and inversely related to size. Smaller corals gained more proportional area

155 relative to larger colonies. The year with the most negative growth was 2009-2010, with the

156 following years slightly less negative (Fig 5). The overall change in $P$. superfusa cover from

1572009 to $2010\left(\mathrm{C}_{2010}-\mathrm{C}_{2009}\right)$ was negative (one sample t-test on $\mathrm{C}_{2010}-\mathrm{C}_{2009}, \mathrm{p}<0.001$ ) with no

158 clear differences among sites (Tukey post-hoc). The change in cover from 2010 to $2011\left(\mathrm{C}_{2011^{-}}\right.$

$159 \mathrm{C}_{2010}$ ) was minimal growth (one sample t-test on $\mathrm{C}_{2011}-\mathrm{C}_{2010}, \mathrm{p}<0.001$ ), followed by a slightly

160 negative change from 2011 to 2012 (one sample t-test, $p=0.09$, Fig 5). There was no statistical

161 artifact associated with including repeatedly measured colonies, i.e., colonies with multiple

162 transition data through time, in the ANCOVA analysis, as the results from bootstrapped

163 subsampled data were comparable to those from the entire dataset (in only one iteration of the

164 random resampling was a significant site effect was noted).

165 We recorded a significant relationship between initial size of a coral colony in 2009 and

166 survival across time points (Fig 6). Larger corals had the greatest declines in area, but they were

167 more likely to survive across time points. The size of the colony in 2009 predicted survival in 
168 2012, with larger colonies showing a higher probability of survival (binary logistic regression, $p$

$169<0.05$, for all time points). Figure 6 depicts the frequency of colony size classes and their

170 survival from 2009 to 2012. The pattern is bimodal, with an increase in frequencies in the

171 smaller corals, followed by a sharp decrease and then a slight increasing pattern of size. The size

172 frequency between the two groups (survivors and non-survivors) was similar, however the

173 largest size classes all survived to the end of the study, while the smaller size classes were more

174 abundant across all years (Fig 6). The average size of colonies varied from approximately $5 \mathrm{~cm}^{2}$

175 to $14 \mathrm{~cm}^{2}$.

176

177 Discussion

178 The goal of this study was to quantify the population dynamics of a common encrusting 179 coral during and after an ENSO event on a remote reef in the central Pacific. The effects of the

180 ENSO warm-water event on the population of Porites superfusa on the forereef on Palmyra Atoll

181 were dramatic and widespread. The ENSO event was associated with temperatures up to $30^{\circ} \mathrm{C}$ at

182 the sites surveyed in 2009 (Maximum degree heating weeks 16, Williams et al., 2010), and in our

183 results $P$. superfusa suffered high mortality rates for over a year after the bleaching event.

The fates of colonies tracked through time revealed that the mechanisms of growth and

185 death changed in surprising ways. After the bleaching event in 2009, corals suffered widespread

186 mortality. Although, clonal growth (colony expansion) was recorded in a subset of individuals,

187 complete and partial mortality were sufficiently large so as to overcome the signal of minimal

188 growth (Supplementary Table 1). Regrowth (from colony expansion and resurrected recruits)

189 was an important driver of recovery and contributed to over $50 \%$ of the increase in cover of $P$.

190 superfusa. Growth of corals in cryptic habitats, such as crevices or areas shaded by other corals, 
191 may be responsible for some of this survival and growth. In 2010, after the mortality event,

192 colony growth increased. This is consistent with other documented case studies, which suggest

193 that corals may increase growth rates to heal after injury (e.g., Kramarsky-Winter \& Loya 2000).

194 However, the recorded increase in growth contradicts the idea that bleaching may decrease

195 regeneration abilities of some corals (Meesters \& Bak 1993).

196 Resurrected recruits played a surprising role in the coral's population growth (over $12 \%$

197 of total growth). The resurrected recruits could be a type of regrowth of cryptic tissue, beyond

198 the observational scope of this study. Some of the regrowth appeared to be emerging out from

199 underneath coral species that were shading the underlying benthos, such as Pocillopora

200 meandrina, and this survival could indicate that partial mortality was induced from UV stress in

201 exposed portions of the benthos (Baird \& Marshall 2002). However, in many cases, the

202 resurrected recruits appeared on a flat reef surface, emerging from benthic areas apparently

203 covered in turf or crustose coralline algae. Unfortunately, the resolution of the photographs did

204 not allow us to determine without question how the corals may have resurrected, for example,

205 from a surviving piece of tissue in a small crevice or otherwise obscured from view.

206 Alternatively, it is possible that these patterns represent true recruitment of larvae onto the exact

207 same location as an adult colony had formerly occupied. Nonetheless, these observations hint at

208 the modularity of coral colonies, and the spatial consistency among 'new' recruits is intriguing

209 and warrants further investigation.

210 In certain cases the partial mortality of $P$. superfusa resulted in fragmentation (100

211 colonies) or clone fission (79 colonies). Fragmented coral colonies living in close proximity

212 (groups of daughter clones) have a potentially higher rate of survival, as they are not as easily

213 eliminated from disease or competition (Highsmith 1982). However, fragmentation in this study 
214 was relatively low $(<10 \%)$, and thus it is unclear if the "fused" colonies $(<10 \%)$ were more likely

215 to survive. While recruitment is important for some coral recovery, within-colony expansion and

216 regrowth were of comparable quantitative importance regarding $P$. superfusa growth at Palmyra

217 Atoll. Some Porites spp. have been found to have a limited capacity for recruitment (Potts et al.,

218 1985), which may make regrowth a specifically useful recovery mechanism for this genus. A

219 recent study by Roff and colleagues (2014) found that regrowth was an important contributor to

220 the population-scale recovery of massive Porites. The ability of corals to regrow from remnant

221 polyps may prove vital to recovery as climate change continues. If the regrowth of smalll

222 fragments of remnant tissue can bring colonies back from apparent mortality, then colonies that

223 appear dead in traditional coral surveys may actually have a chance at survival. As a result,

224 traditional coral surveys may overemphasize mortality.

225 Coral colony size was an important predictor of the coral's ultimate fate (Fig 6).

226 Interestingly, $P$. superfusa seemed to have size-dependent growth and death. Growth decreased

227 with increasing size, suggesting that this species may have determinate growth. This growth

228 pattern could be due to high levels of partial mortality. In addition, as is consistent with the

229 literature, smaller colonies of $P$. superfusa experienced higher rates of overall change, including

230 mortality and recovery (Hughes \& Jackson 1985). Large colonies are more likely to suffer partial

231 mortality, which may be part of the declining growth with size phenomenon (Hughes \& Jackson

232 1985). Probabilistically, larger colonies are more likely to suffer injury due to a larger surface

233 area, and this may be a factor in the decline of overall growth. Smaller colonies tend to

234 experience damage in a more binary way: either resisting disturbance entirely or dying

235 completely, suffering less incidence of partial mortality (Connell 1973; Hughes \& Jackson

236 1985). 

temperature events, it is important to note that recovery did not exceed mortality over the course

239 of this study. The decline in P. superfusa cover from 2009 to 2010 occurred more rapidly than

240 the increase in coral cover from 2010 to 2011 and the decline from 2011 to 2012. Full population

241 recovery is a slow process, and the longer-term trajectory of $P$. superfusa on Palmyra remains to 242 be seen.

243 Understanding the effects of large-scale phenomena on community dynamics in relatively

244 pristine reefs provides critical benchmarks for coral demography (Edmunds 2002). Further

245 studies on this topic will help quantify the importance of fragmented or remnant corals for reef

246 recovery processes. Examination of other species at these sites may provide important

247 comparisons among morphologies and between species with different life history strategies, 248 which combined may help infer the likelihood of community level recovery. The causes of 249 bleaching, mortality, resistance, and recovery are clearly complex and species-specific. Thus, 250 additional studies from remote Pacific island coral communities are important for understanding 251 the capacity of these systems for recovery via different mechanisms; such studies will help to 252 directly improve the policies for protection of reefs worldwide.

\section{Conclusions}

255 This study documented a bleaching event and subsequent change in areal cover of a 256 common coral on a remote central Pacific atoll. Coral populations can change via four different 257 dynamic processes: complete mortality, partial mortality, growth, and true larval recruitment. 258 This study suggests a fifth dynamic, 'resurrected' recruits, as a mechanism contributing to coral 
259 recovery. Additional research is needed to determine the source of this coral growth (e.g., 260 exploitation of cryptic habitats, regrowth of remnant tissue),.

261 With increasing climate pressures, many coral reefs have experienced rapid decline. In 262 such cases, tissue loss due to mortality is faster and more obvious than tissue gain due to growth.

263 Coral growth is often slow and subtle, making it a difficult research and management target for 264 short time scales. Despite the challenges associated with quantification, regrowth is a critical 265 process in coral recovery, and it is vital we understand the mechanisms controlling it. The 266 implications from this study of colony-specific patterns of decline and recovery should be scaled 267 up to examine the role of regrowth and the future of remote Pacific islands' reef recovery. 


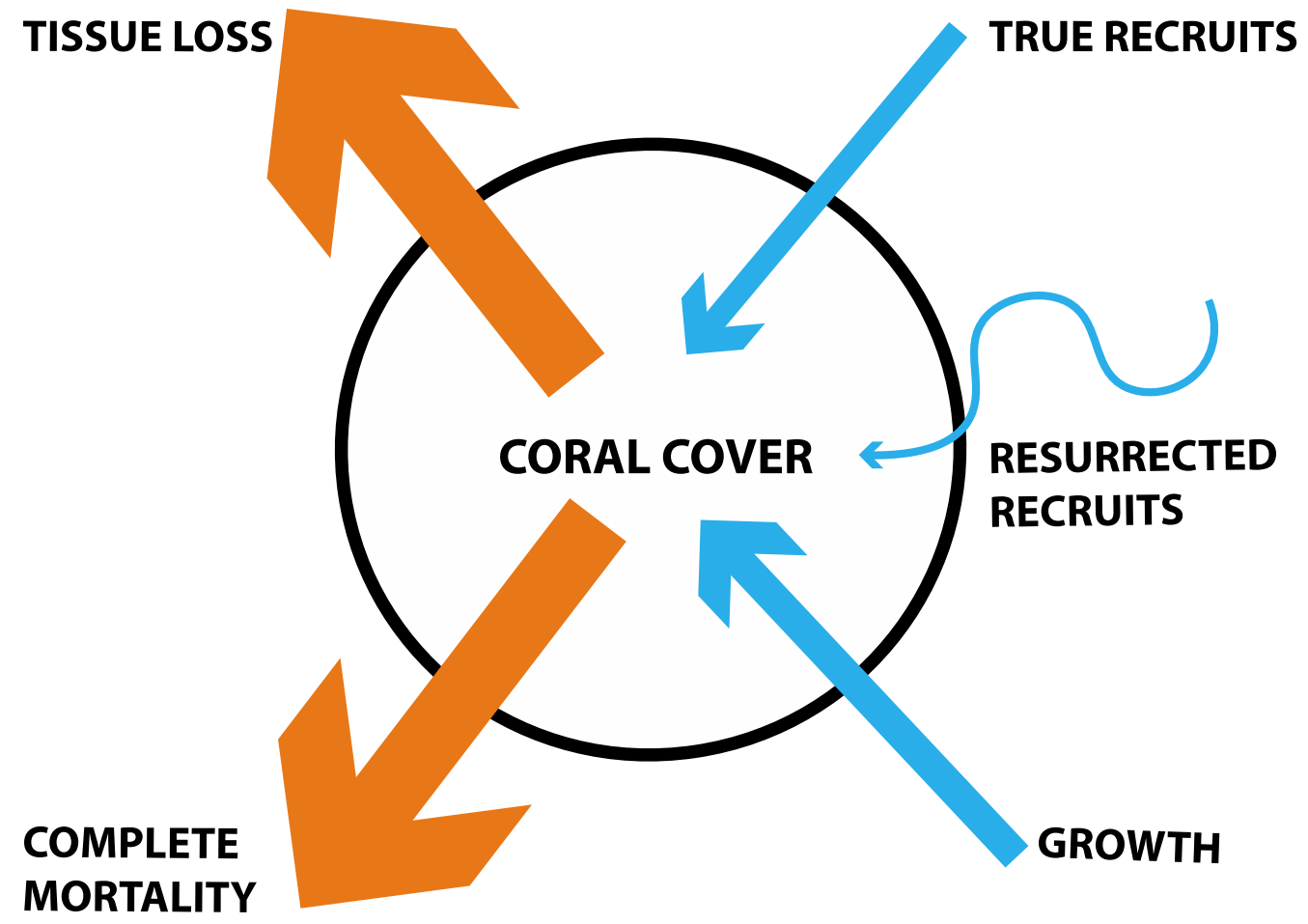

274 Figure 1. Conceptual diagram of coral demographics contributing to total coral cover for a 275 population. Blue (right side) arrows denote contribution to increasing coral cover (e.g., True 276 recruits, 'Resurrected' recruits, and Growth). Orange (left side) arrows denote contribution to 277 decreasing coral cover (e.g., Partial mortality and Complete mortality). 'Resurrected recruits' is a 278 new term, an operationally defined form of regrowth (see Methods for detailed description). The 279 thickness of arrows indicates the mechanism's relative contribution, as found in this study. 


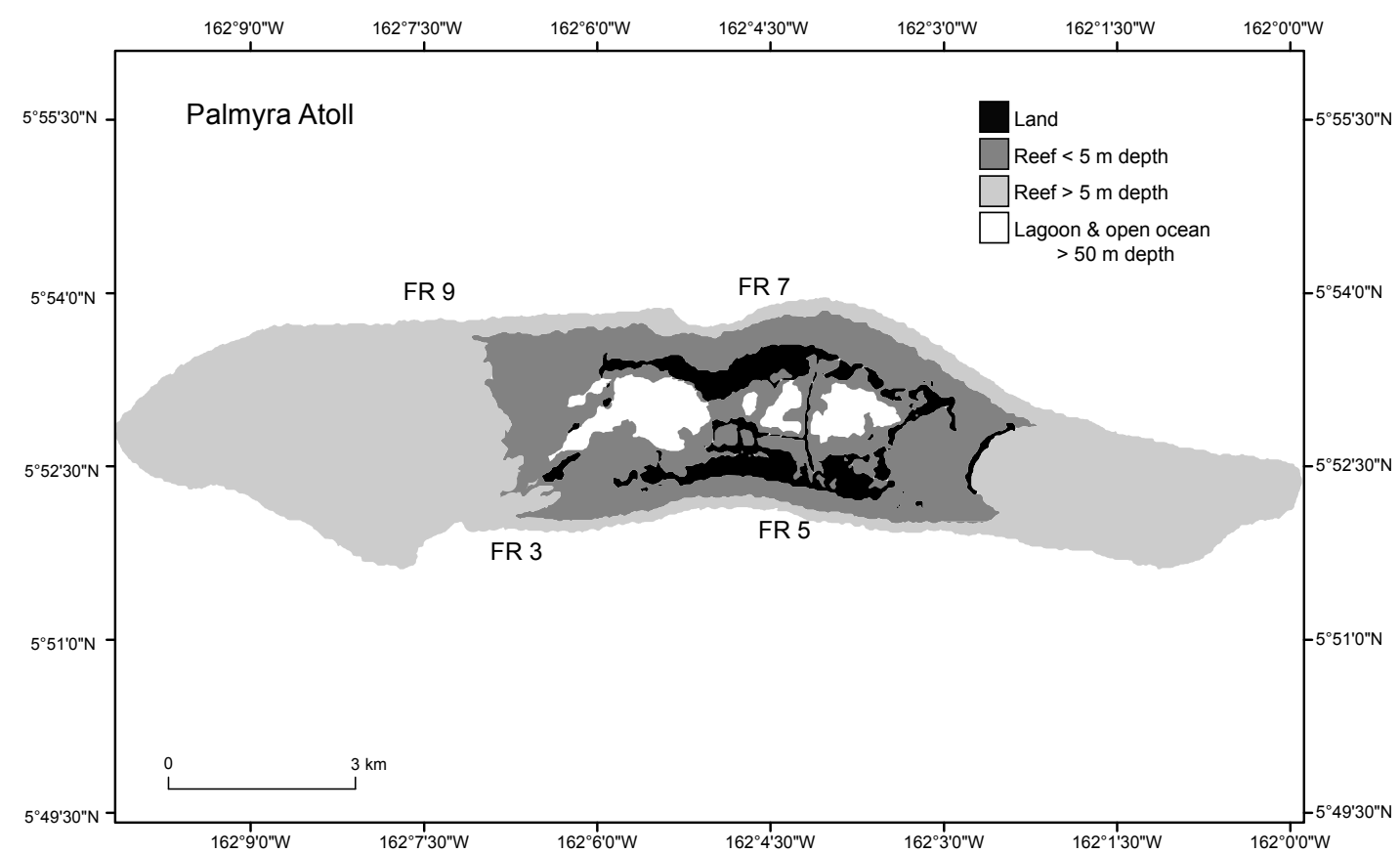

285 Figure 2. Study sites (FR3, FR5, FR7, FR9) around Palmyra Atoll. Palmyra is located in the 286 remote central Pacific. The black area shows the atoll land area and the gray and white areas 287 denote different depth strata of reef and open ocean.

288

289 


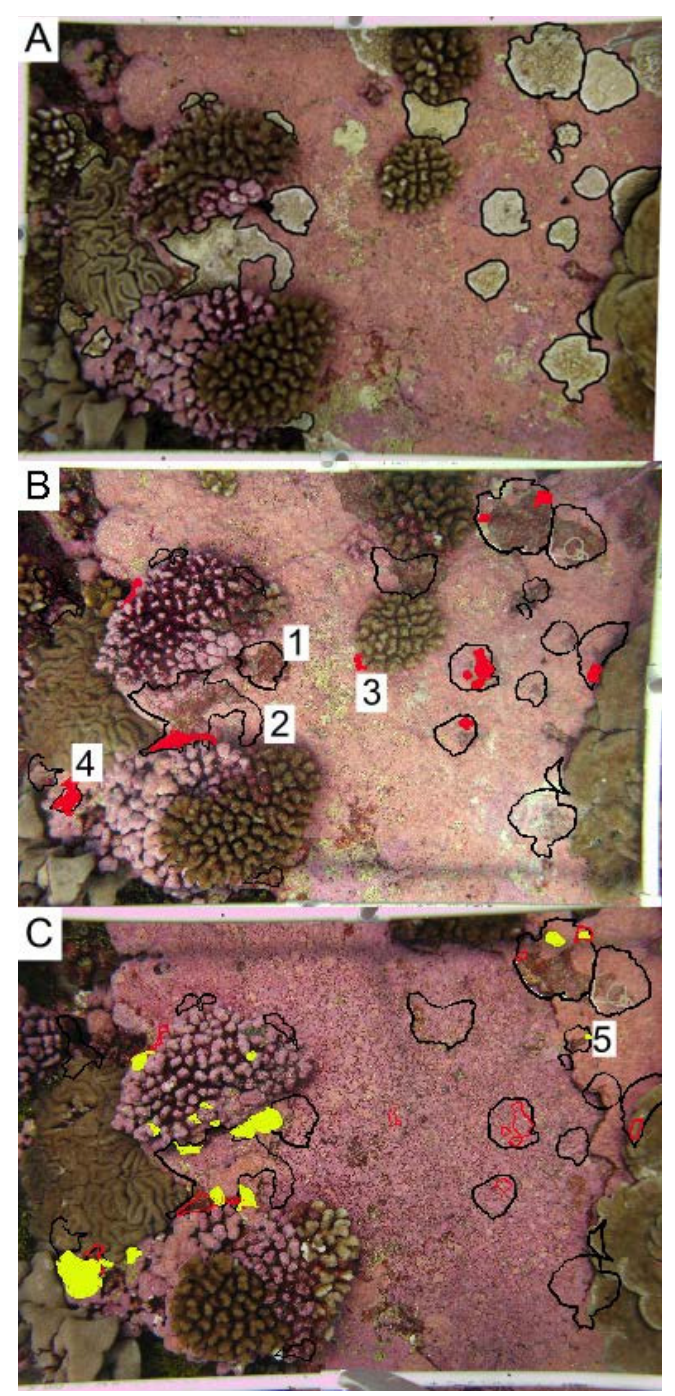

291 Figure 3. Representative permanent photoquadrat sequence from one site (FR9). (A) September

$2922009\left(\mathrm{C}_{2009}\right)$ with living Porites superfusa outlined in black. (B) July $2010\left(\mathrm{C}_{2010}\right)$ with previous

2932009 colony area outlined in black, and living coral highlighted in red. (C) September 2011

$294\left(\mathrm{C}_{2011}\right)$ with previous 2009 colony area outlined in black, 2010 colony area outlined in red, and

295 living coral highlighted in yellow. Colonies that show examples of different fates are labeled

296 with numbers: (1) complete mortality, (2) partial mortality, (3) true recruitment, (4) growth, and

297 (5) resurrected recruits. Quadrats are $0.6 \mathrm{~m}^{2}$. 


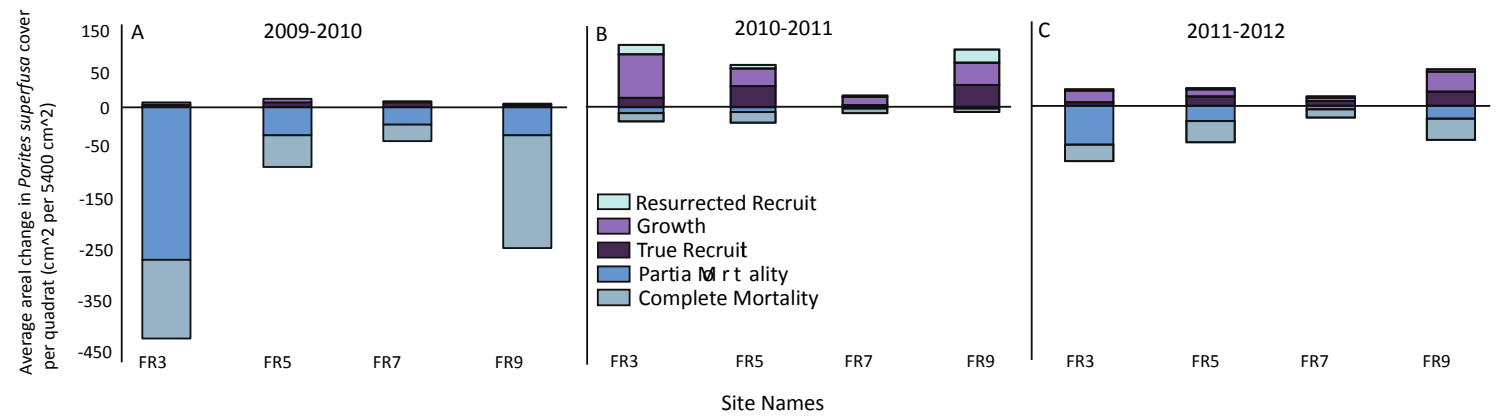

299

300

301 Figure 4. Patterns of gain and loss for Porites superfusa during- and post-bleaching event. (A)

3022009 to 2010 change in cover, (B) 2010 to 2011 change in cover, (C) 2011 to 2012 change in

303 cover. 'Resurrected' recruits do no exist within the first time transition, as no data exists prior to 3042009.

305

306

307 


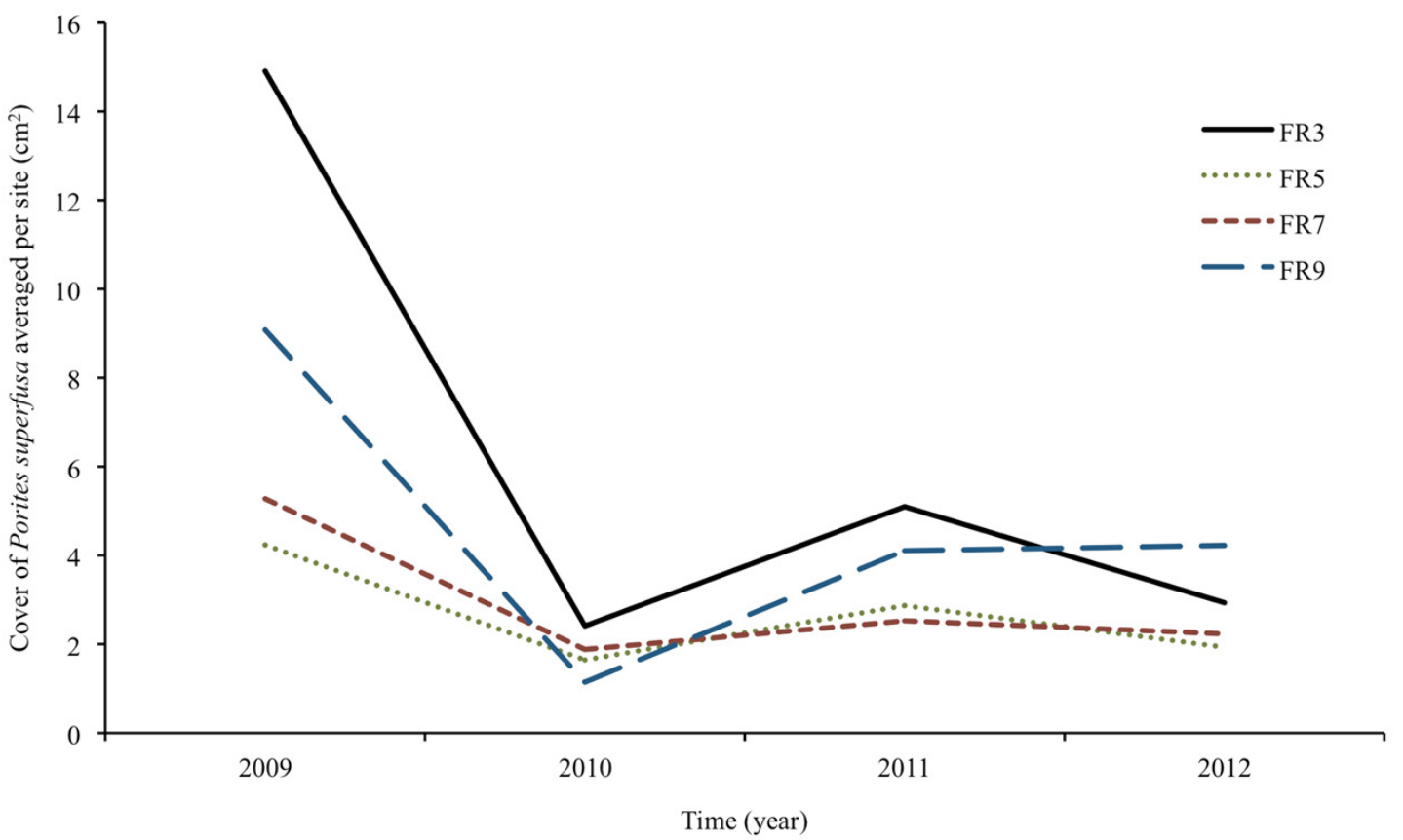

310 Figure 5. Porites superfusa cover from 2009 to 2012, averaged by site through time, at yearly

311 surveys. ENSO event occurs in 2009. Sites (denoted by different lines) follow similar patterns

312 through time. Cover decline is followed by variations in recovery and further decline. Figure 2

313 map shows site locations around island.

314

315

316

317

318

319

320

321 


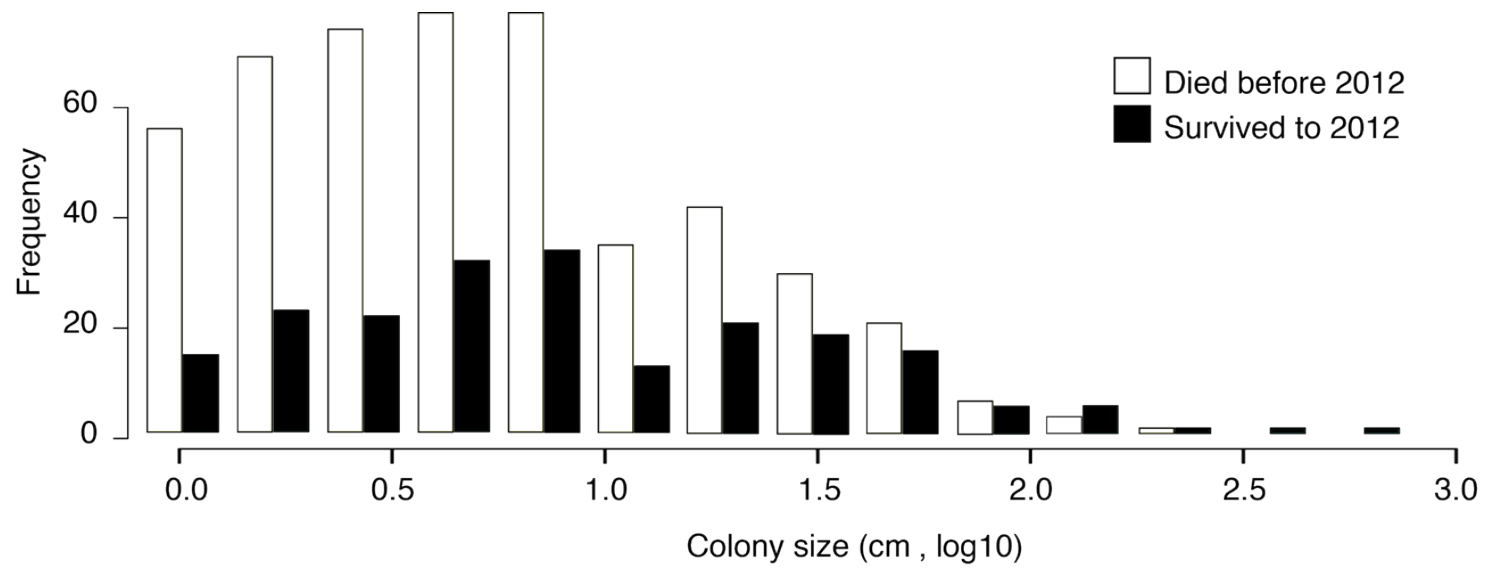

322

323 Figure 6. Paired histogram of initial colony size (in 2009) and survivorship (to 2012). Larger

324 coral colonies were more likely to survive from 2009 to 2012 . White denotes coral colonies that 325 died before the 2012 survey. Black denotes coral colonies that survived to 2012. 
329 Special thanks to Ben Knowles, Genivaldo Gueiros, Clint Edwards for their edits on the 330 manuscript. Field work completed with the help of Maggie Johnson and Amanda Carter. 


\section{References}

333 Abramoff MD, Magalhaes PJ, Ram SJ (2004) Image Processing with ImageJ.

$334 \quad$ Biophotonics Int 11:36-42

335 Baird AH, Marshall PA (2002) Mortality, growth and reproduction in scleractinian coral 336 following bleaching on the Great Barrier Reef. Mar Ecol Prog Ser 237:133-141

337 Brown BE, Suharsono (1990) Damage and recovery of coral reefs affected by El-Nino

338 related seawater warming in the Thousand Islands, Indonesia. Coral Reefs 8:163-170

339 Chadwick NE, Loya Y (1990) Regeneration after experimental breakage in the solitary reef coral $340 \quad$ Fungia granulosa, Klunzinger 1879. J Exp Mar Biol Ecol 142:221-234

341 Connell JH (1973) Population ecology of reef building corals Pp 205-245. In Jones, O.A., Endean, R. (eds) Biology and Ecology of Coral Reefs. Vol 2. Academic Press, New York

Diaz-Pulido G, McCook LJ, Dove S, Berkelmans R, Roff G, Kline DI, Weeks S, Evans RD, 345 Williamson DH, Hoegh-Guldberg O. (2009) Doom and boom on a resilient reef: Climate change, algal overgrowth and coral recovery. PLoS ONE 4(4):e5239

Dollar SJ, Tribble GW (1993) Recurrent storm disturbance and recovery: a long term study of coral communities in Hawaii. Coral Reefs 12:223-233

Gilmour JP, Smith LD, Heyward AJ, Baird AH, Pratchett MS (2013) Recovery of an isolated coral reef system following severe disturbance. Science 340:69-71

351 Harper, JL (1985) Modules, branches, and the capture of resources. Population Biology and Evolution of Clonal Organisms. (Eds.) Jackson, JBC., LW Buss, RE Cook. Yale University Press. New Haven and London 
355 Highsmith RC (1982) Reproduction by fragmentation in corals. Mar Ecol Prog Ser $356 \quad 7: 207-226$

357 Hughes TP, Jackson JBC (1980) Do corals lie about their age? Some demographic 358 consequences of partial mortality, fission, and fusion. Science 209:713-715

Hughes TP, Jackson, JBC (1985) Population dynamics and life histories of foliaceous corals. Ecol Mono 55:141-166

361 Hughes TP, Ayre D, Connell JH (1992) The evolutionary ecology of corals. TREE 7(9):292-295

363 Knowlton N, Jackson JBC (2008) Shifting baselines, local impacts, and global change on coral reefs. PLoS Biol 6:e54

365 Kramarsky-Winter E, Loya Y (2000) Tissue regeneration in the coral Fungia granulosa: the effect of extrinsic and intrinsic factors. Mar Biol 137:867-873

Madin JS, Baird AH, Dornelas M, Connolly SR (2014) Mechanical vulnerability explains size-dependent mortality of reef corals. Ecol Lett 17(8):1008-15

Marshall PA, Baird AH (2000) Bleaching of corals on the Great Barrier Reef: differential susceptibilities among taxa. Coral Reefs 19:155-163

371 McCook LJ, Jompa J, Diaz-Pulido G (2001) Competition between corals and algae on coral reefs: a review of evidence and mechanisms. Coral Reefs 19: 400-417

373 Meesters EH, Bak RPM (1993) Effects of coral bleaching on tissue regeneration potential and colony survival. Mar Ecol Prog Ser 96:189-198

375 Potts DC, Done TJ, Isdale PJ, Fish DA (1985) Dominance of a coral community by the 376 genus Porites (Scleractinia). Mar Ecol Prog Ser 23:79-84 
377 Roff G, Bejarano S, Bozec YM, Nugues M, Steneck RS, Mumby PJ (2014) Porites and the

378 Phoenix effect: unprecedented recovery after a mass coral bleaching event at Rangiroa

379 Atoll, French Polynesia. Mar Biol 161 (6):1385-1393

380

381

382 383

384

385

386

387

388

389

390

391

392

393

Sandin SA, Smith JE, DeMartini EE, Dinsdale EA, Donner SD (2008) Baselines and degradation of coral reefs in the Northern Line Islands. PLOS ONE 3:e1598

Williams GJ, Knapp IS, Maragos JE, Davy SK (2010) Modeling patterns of coral bleaching at a remote Central Pacific atoll. Mar Poll Bull 60:1467-1476

Williams GJ, Knapp IS, Aeby GS, Davy SK (2011) Spatial and temporal patterns of scleractinian coral, soft coral, and zoanthid disease on a remote, near-pristine coral reef (Palmyra Atoll, central Pacific). Dis Aquat Org 94:89-100

Williams GJ, Price NN, Ushijima B, Aeby GS, Callahan S, Davy SK, Gove JM, Johnson MD, Knapp IS, Shore-Maggio A, Smith JE, Videau P, Work TM (2014) Ocean warming and acidification have complex interactive effects on the dynamic of a marine fungal disease. Proc R Soc B 281:20133069

Veron, J.E.N. (1995) Corals in Space and Time: The Biogeography and Evolution of the Scleratinia. Cornell University Press 